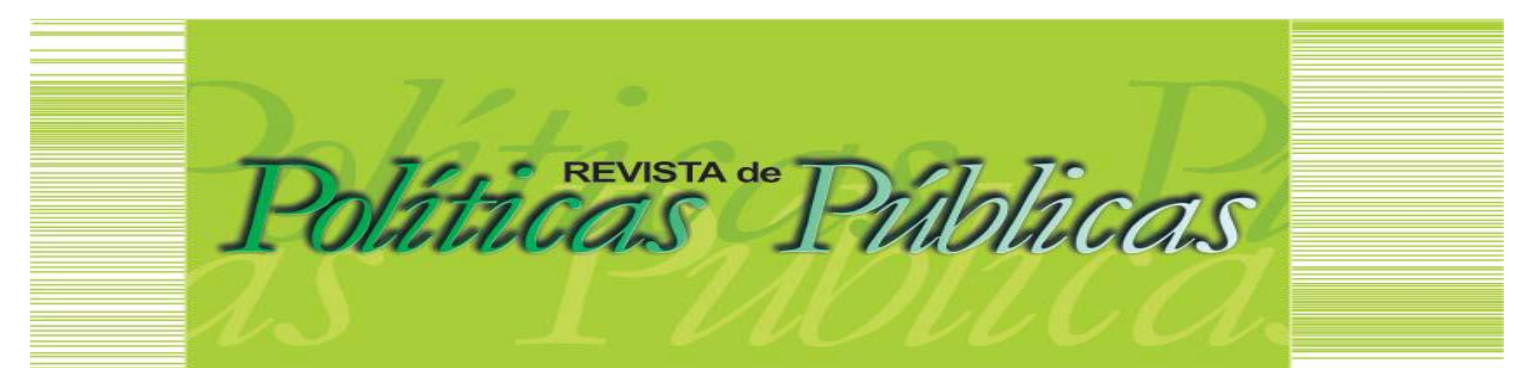

\title{
AUDIÊNCIA DE CUSTÓDIA E SUA IMPLEMENTAÇÃO NA PRÁTICA PROCESSUAL PENAL DO ESTADO DO MARANHÃO
}

\author{
Carlos Hélder Carvalho Furtado Mendes ${ }^{1}$ \\ José Guimarães Mendes Neto²
}

\begin{abstract}
Resumo:
O presente trabalho faz uma breve síntese acerca da Audiência de Custódia e como se deu (ou se tem dado) sua inserção no Direito brasileiro, trazendo à baila dados estatísticos do Tribunal de Justiça do Estado do Maranhão na medida em que se pretende ilustrar os avanços acerca da aplicação e efetividade do referido instituto processual penal naquele Estado. Além de reafirmar a necessidade do instituto na construção de um Processo penal mais humano, descreve todo o percurso legislativo e social que a Audiência de Custódia tem enfrentado. Por fim, através das informações colhidas, em campo prático, pela Unidade de Monitoramento Carcerário do TJMA, demonstra uma redução interessante do número de pessoas que não voltam a - supostamente - se envolver em conflitos com a justiça, após um primeiro contato com a Audiência de Custódia.
\end{abstract}

Palavras-chave: Audiência de Custódia. Implementação. Devido Processo Penal.

\section{CUSTODY HEARING AND ITS IMPLEMENTATION IN THE PROCESSUAL PRACTICE OF THE STATE OF MARANHÃO}

\section{Abstract:}

This paper briefly summarizes the Hearing of Custody and how it has been (or has been given) its insertion in Brazilian Law, bringing to the fore statistical data of the Court of Justice of the State of Maranhão insofar as it is intended to illustrate the advances concerning the application and effectiveness of said criminal procedure institute in that State. In addition to reaffirming the institute's need to build a more humane criminal process, it describes all the legislative and social path that the Hearing of Custody has faced. Finally, through the information collected by the TJMA's Prison Monitoring Unit in a practical field, it shows an interesting reduction in the number of people who do not return to - supposedly - to become involved in conflicts with justice, after a first contact with the Audience of Custody.

Keywords: Custody Hearing. Implementation. Due to Criminal Procedure.

Artigo recebido em: 21/01/2019 Aprovado em: 06/04/2019 DOI: http://dx.doi.org/10.18764/2178-2865.v23n1p81-96

\footnotetext{
${ }^{1}$ Especialista em Direito Penal Econômico pela Universidade de Coimbra/IBCCRIM. Especialista em Ciências Penais pela Universidade Anhanguera/Uniderp. Bolsista Capes-Prosup. Doutorando e Mestre em Ciências Criminais pela PUC/RS. Email: carloshmendes@gmail.com

2 Advogado. Especialista em Direito Penal Econômico pelo Instituto Brasileiro de Ciências Criminais (IBCCRIM) e Instituto de Direito Penal Econômico e Europeu (IDPEE), da Faculdade de Direito da Universidade de Coimbra. Mestre em Direito Constitucional pelo Instituto de Direito Público (IDP/DF). Especialista em Direito Eleitoral pela Pontifícia Universidade Católica de Minas Gerais (PUC/MG). E-mail: guimaraesmneto@hotmail.com
} 


\section{INTRODUÇÃO}

Antes de começar o ponto principal do artigo, são necessárias algumas notas. Não se discorrerá acerca da ampliação da malha do controle penal do Estado através da adoção de medidas cautelares diversas da prisão. A opção metodológica do presente escrito se deu inteiramente em demonstrar o percurso de implementação da audiência de custódia no cenário maranhense, bem como os reflexos disso.

Pois bem, por meio dos decretos $n^{0} 592$ e 678 do ano de 1992, o Brasil promulgou 0 Pacto Internacional dos Direitos Civis e Políticos (PIDCP), bem como a Convenção Americana de Direitos Humanos (CADH). Tais diplomas estabelecem que qualquer pessoa presa, detida, retida ou encarcerada em virtude de infração penal deverá ser conduzida, sem demora, à presença do juiz ou de outra autoridade habilitada por lei a exercer funções judiciais. No Brasil, tal ato processual recebeu 0 nome de Audiência de Custódia.

O instituto da Audiência de Custódia proporciona à prática processual penal brasileira uma compatibilização com tratados internacionais que já dispõem sobre a matéria. Tem-se como importante a investigação de como está sendo aplicado o instituto da Audiência de Custódia no direito brasileiro e como tem ocorrido a efetividade do instituto no Estado do Maranhão.

Para tanto, buscou-se, como objetivo geral, apontar como se deu a observância da Convenção Americana de Direitos Humanos, no que toca ao Instituto da Audiência de Custódia, e sua aplicação na prática processual penal do Estado do Maranhão.

No primeiro capítulo optou-se por demonstrar o avanço democrático e civilizatório, quanto à humanização do Processo Penal brasileiro a partir da realização da Audiência de Custódia.

No segundo, descrever o processo de inserção da Audiência de Custódia no Direito Brasileiro, destacando, sobretudo, o caráter supralegal das normas advindas de Tratados internacionais que versem sobre Direitos Humanos.

E, por fim, no terceiro, discorrer sobre a aplicação e a efetividade da Audiência de Custódia no Estado do Maranhão, a partir de dados estatísticos coletados pela Unidade de Monitoramento Carcerário do Tribunal de Justiça do Estado.

As técnicas metodológicas adotadas são a bibliográfica, jurisprudencial e documental. Nesta última se faz um estudo cronológico desde a implementação da audiência de custódia no direito brasileiro, até a sua implementação na realidade processual maranhense por documentos e resoluções, tanto do Tribunal de Justiça do Maranhão quanto do Conselho Nacional de Justiça. Coletaram-se dados fornecidos pelo Tribunal de Justiça do Estado do Maranhão, nomeadamente a Unidade de Monitoramento e Fiscalização do Sistema Carcerário, dos anos de 2014 a 2016, que 


\section{AUDIÊNCIA DE CUSTÓDIA E SUA IMPLEMENTAÇÃO NA PRÁTICA PROCESSUAL PENAL DO ESTADO DO MARANHÃO}

demonstram a quantidade de audiências de custódia ocorridas no Estado, a porcentagem de revogações de prisão a partir da audiência de custódia.

2 AUDIÊNCIA DE CUSTÓDIA: é preciso humanizar o processo penal brasileiro

A audiência de custódia consiste em uma efetivação do direito do acusado, de que todo cidadão preso deve ser conduzido, sem demora, à presença do Juiz para que este faça cessar eventuais abusos, maus tratos e torturas, bem como que promova o debate acerca da legalidade circunstancial que decorreu 0 ato de prisão e a sua necessidade. (LOPES JR; PAIVA, 2014). Logo, funcionaria como mecanismo de controle estatal.

Tal medida é tema das mais atuais discussões que perpassam pelas ciências criminais e já demonstra um verdadeiro avanço processual brasileiro rumo à ordem civilizatória. Tudo porque 0 Brasil, signatário do Pacto Internacional dos Direitos Civis e Políticos (PIDCP), bem como da Convenção Americana de Direitos Humanos (CADH), deve obedecer aos ditames estabelecidos pelas respectivas previsões normativas.

Segundo Giacomolli (2015) ao serem ratificados pelo Brasil, o país assumiu a obrigação de aplicar as regras do devido processo, mormente as assecuratórias da liberdade, e o cumprimento de medidas protetivas a direitos humanos em todo o seu território e por todas as suas instituições, poderes, agentes públicos e cidadãos.

As referidas disposições estabelecem, em seus artigos 9.3 e 7.5, respectivamente, que qualquer pessoa presa, detida, retida ou encarcerada em virtude de infração penal deverá ser conduzida, sem demora, à presença do juiz ou de outra autoridade habilitada por lei a exercer funções judiciais. Ambas promulgadas em 1992, através dos decretos $n^{0} 592$ e $n^{0} 678$, deveriam ter aplicabilidade imediata, eficaz e integral. Entretanto, nunca foram cumpridas a rigor. (SANTOS, 2015).

Fato este incoerente, pois, como discorrem Mendes e Branco (MENDES; BRANCO, 2015; SARLET; MARINONI; MITIDIERO, 2012), os direitos decorrentes de tratados sobre Direitos Humanos, embora não abarcados pelo status constitucional, possuem caráter supralegal.

Afirmam os autores (MENDES; BRANCO, 2015; SARLET; MARINONI; MITIDIERO, 2012), que após a Emenda Constitucional $n^{0}$ 45/2004, as normas decorrentes de tratados internacionais sobre direitos humanos possuem caráter infraconstitucional, mas supralegal, ou seja, estará abaixo das normas constitucionais, mas acima de todas as demais normas infraconstitucionais. Esse também é 0 entendimento encontrado em jurisprudência ${ }^{1}$ do Supremo Tribunal Federal.

Desse modo, deverá existir uma dupla compatibilidade das normas hierarquicamente inferiores a tais dispositivos. A primeira referente à Constituição Federal, ou seja, exercício do controle de constitucionalidade, no qual normas incompatíveis com os ditames da Carta Magna serão 
declaradas inconstitucionais. A segunda, por sua vez, referente à Convenção Americana de Direitos Humanos, chamado de controle de convencionalidade das leis, em que há uma adequação hierárquica das normas inferiores à supralegalidade das convenções que versem sobre Direitos Humanos.

No que tange à prática processual penal, trata-se, pois, de sua humanização, vez que não raras são as persecuções criminais brasileiras que

\section{[...] estão enclausuradas na esfera ordinária do processo penal, permanecendo impermeáveis às novas metodologias e à complexidade das exigências contemporâneas; permanecem reféns de uma compreensão paleopositivista, gerada pela inflação legislativa, pela perda da referência constitucional e convencional humanitárias. (GIACOMOLLI, 2015, p. 12.).}

Segundo Giacomolli (2015), há que se praticar uma nova metodologia hermenêutica, pautada em uma leitura convencional e constitucional do processo penal. Somente assim é que se sustentará o processo penal humanitário, passo para a evolução civilizatória na aplicação da punição. Por isso, "[...] há que se falar em processo penal constitucional, convencional e humanitário, ou seja, do devido processo." (GIACOMOLLI, 2015, p. 12).

O que se depreende, portanto, é que a Audiência de Custódia, para além de seus objetivos humanitários, funciona como regra processual penal, na medida em que decorrente de norma supralegal se transforma em instituto processual interno de garantia e respeito a direitos fundamentais e processuais.

Sendo, portanto, de aplicação imediata, não haveria que se falar em necessidade de previsão em texto constitucional ou processual penal para seu cumprimento, pois, como dito, essas regras já possuem amparo e força normativa no Brasil.

Entretanto, em âmbito nacional existe certa resistência e reserva dos operadores do direito em reconhecer a plena aplicabilidade de textos internacionais que não tenham sido incorporados de forma expressa à legislação interna. (ANDRADE; ALFLEN, 2016).

Afirmam Andrade e Alflen (2016) que, dessa resistência, é que derivaram algumas iniciativas de ordem legislativa para internalizar a referida audiência em nossa legislação, e mais além, para que se estabelecesse um procedimento único a ser observado quando de sua realização.

\section{INSERÇÃO DA AUDIÊNCIA DE CUSTÓDIA NO DIREITO BRASILEIRO}

Tímido debate sobre o instituto da Audiência de Custódia se deu na tramitação do Projeto Lei Senado $n^{0} 156$, de 2009. Tendo como proposta inovadora a figura do juiz de garantias, trouxe consigo, dentre as diversas atribuições, a de zelar pela observância dos direitos do preso, podendo determinar que este seja conduzido à sua presença². Porém, o caráter facultativo emitido pelo valor semântico derivado do verbo poder, não reflete a obrigatoriedade da apresentação em Audiência, como 


\section{AUDIÊNCIA DE CUSTÓDIA E SUA IMPLEMENTAÇÃO NA PRÁTICA PROCESSUAL PENAL DO ESTADO DO MARANHÃO}

bem vigora nos dispositivos internacionais. Dessa forma, não poderia se considerar tal disposição como precursora da Audiência de Custódia no Brasil. (ANDRADE; ALFLEN, 2016).

Destacam-se, porém, as Emendas $n^{0} 170^{3}$ e $n^{0} 171$ (BRASIL, 2009a) , propostas pelo Senador José Sarney, que visava substituir o teor do artigo $551^{\circ}$ e $553^{\circ}$, do PLS 156, de 2009, na medida em que regulamentava a apresentação ao juiz competente, dentro de 24 horas depois da prisão, o preso em flagrante. Tinha-se como justificativa a adequação da norma processual penal brasileira aos ditames convencionais, porém ambas as emendas foram rejeitadas no parecer final emitido pelo Senador Renato Casagrande. (BRASIL, 2010).

Segundo Casagrande, o motivo para que fosse rejeitada a proposta da emenda $n^{0} 170$ seria que esta conflitava com as normas internacionais que a justificavam (PIDCP e CADH), vez que ainda segundo o Senador - "[...] as próprias normas internacionais citadas na justificativa abrem a possibilidade de que o preso seja conduzido à presença de 'outra autoridade habilitada/autorizada por lei a exercer funções judiciais'." que na equivocada interpretação do Senador, era papel, em nosso ordenamento, exercido pelo delegado de polícia judiciária. (BRASIL, 2010).

Assim, entende-se por necessário o esclarecimento acerca da competência para presidir a audiência de custódia. Por mais que exista a discussão quanto à possibilidade de o Delegado de Polícia realizar a referida audiência, em virtude da CADH e do PIDCP, essa argumentação não deve proceder. (SANTOS, 2015).

Conforme o raciocínio de Santos (SANTOS, 2015), embora o artigo $7.5^{\circ}$ da CADH disponha "[...] que toda pessoa presa, detida ou retida deve ser conduzida, sem demora, à presença do juiz ou outra autoridade autorizada por lei a exercer funções judiciais.", jamais poderia ser o Delegado de Polícia essa outra autoridade.

O autor lembra que este não é autorizado pela lei a exercer funções judiciais, na medida em que a Constituição Federal o proíbe de praticar ato acobertado pela reserva de jurisdição. Ademais, careceria de razoabilidade e lógica admitir que o agente responsável pela efetiva prisão de alguém, seja o mesmo a exercer o controle quanto à legalidade do ato.

Finaliza Santos (2015), com a argumentação de que muito embora o Delegado de Polícia seja o primeiro agente a garantir direitos fundamentais ao imputado, não é ele pessoa competente para todo e qualquer ato que busque a garantia de direitos fundamentais. O objetivo da audiência, que se dá por meio do contraditório prévio, é garantir direitos do preso a fim de que se possam avaliar todas as circunstâncias que envolvem a prisão efetuada e a manutenção ou não da restrição de liberdade do imputado durante o processo.

Passados pouco mais de dois anos, veio à tona o Projeto Lei Senado $n^{0} 554$, a fim de que se regularizasse a exigência de apresentação do cidadão preso ao juiz, à audiência de custódia. 
(SANTOS, 2015). Frisa-se, porém, que após a ratificação dos dispositivos internacionais, "[...] constrangedoramente, o Poder Legislativo nacional, até 0 ano de 2011, não mais fez qualquer movimento significativo, no sentido de que o sujeito preso tivesse rápido contato pessoal com uma autoridade judicial ou com poderes judiciais para rever os motivos da prisão efetuada". (ANDRADE; ALFLEN, 2016, p. 21.).

Segundo Andrade e Alflen (2016), perdeu-se preciosa oportunidade de suscitar o tema através da Lei $n^{0} 12.403$, de 4 de maio 2011, que reformou parcialmente o Código de Processo Penal brasileiro, quanto às prisões provisórias e medidas cautelares alternativas ao cárcere. Na elaboração da referida Lei, precisamente em seu Artigo 287, se dispôs, em uma acepção mais ampla, o que poderia já ser chamada, à época, de Audiência de Custódia. Conforme o Artigo 287, CPP, "[...] se a infração for inafiançável, a falta de exibição do mandado não obstará à prisão, e o preso, em tal caso, será imediatamente apresentado ao juiz que tiver expedido o mandado". (BRASIL, CPP, 2011).

Ocorre que desde a ratificação da Convenção Americana de Direitos Humanos, em 1992, até a proposição do Projeto Lei Senado n 554 de 2011, ou seja, quase duas décadas, não houve, de fato, movimento efetivo para a concretização e aplicação do referido instituto no cotidiano processual brasileiro. (ANDRADE; ALFLEN, 2016) ${ }^{5}$.

O PLS $n^{0} 554^{\circ}$ de 2011, proposto pelo Senador Antonio Carlos Valadares, teve como justificação, 1) além de regulamentar a apresentação do preso à autoridade judicial, a fim de seja que resguardada sua integridade física e psíquica, 2) adequar o ordenamento jurídico pátrio à prática mundial quando ao respeito a direitos humanos reafirmados quando da ratificação da CADH, 3) também, visava observar que o tal projeto se originou como resultado de diálogos com o Ministério da Justiça, a Secretaria de Direitos Humanos da Presidência da República e organizações de direitos humanos da sociedade civil. (BRASIL, 2011).

Ressalvados os méritos da iniciativa, a partir da análise do Senador Randolfe Rodrigues, conforme citadas - e acatadas de maneira parcial - as sugestões encaminhadas pela Defensoria Pública do Estado de São Paulo, incluiu-se como participantes da Audiência de Custódia o Ministério Público e o Defensor (Particular ou Público). (BRASIL, 2011). Submetido à Comissão de Assuntos Econômicos, cuja presidência era ocupada pelo Senador Lindbergh Farias, o parecer foi aprovado.

Ocorre que, em 22 de maio de 2014, o Poder Judiciário do Estado do Rio de Janeiro (RIO DE JANEIRO, 2014) encaminhou proposta de emenda do Projeto com justificativa respaldada na possibilidade de ser realizada a apresentação do preso em flagrante por meio de videoconferência, uma vez que desta forma também se cumpriria com as garantias de sua integridade física e psíquica. Tal proposta também tem por base metas de redução de circulação de presos pelas ruas da cidade do 


\section{AUDIÊNCIA DE CUSTÓDIA E SUA IMPLEMENTAÇÃO NA PRÁTICA PROCESSUAL PENAL DO ESTADO DO MARANHÃO}

Rio de Janeiro, "[...] tornando possível que sejam evitadas tentativas de resgate que colocam em risco toda a população". (RIO DE JANEIRO, 2014).

A referida proposta foi acatada pelo Senador Francisco Dornelles, que sugeriu emenda ao Projeto, mas que fora rejeitada pelo parecer do Senador Humberto Costa (BRASIL, 2014), em que afirmou não ser o momento oportuno para implementação do sistema de videoconferência.

Em paralelo à conturbada tramitação do PLS n 554, de 2011, diversas instituições se manifestaram, tanto a favor do Projeto, quanto contra. Como exemplo: Associação Nacional dos Delegados de Polícia Federal (ADPF); Federação Nacional dos Delegados de Polícia Federal (FENAPOL); Associação dos Delegados de Polícia do Brasil (ADEPOL/BR); Colégio Nacional dos Defensores Públicos Gerais (CONDEGE); Ministério Público do Estado de São Paulo (MP/SP); Associação dos Juízes Federais do Brasil (AJUFE); Associação Nacional dos Defensores Públicos (ANADEP); Associação Nacional dos Membros do Ministério Público (CONAMP); Instituto Brasileiro de Ciências Criminais (IBCCRIM) ${ }^{6}$.

No tocante à aplicação da audiência de custódia por meio de videoconferência, cabe ressaltar as lições de Rosa (2016, p, 262) que afirma ser de caráter excepcional, conforme a Corte Interamericana de Direitos Humanos, a realização da Audiência de Custódia por meio de Videoconferência, somente justificada de acordo com a situação fática apresentada, "[...] não podendo advir da mera comodidade dos sujeitos (Juiz, Ministério Público e Defensor)".

Ressalta-se que, atualmente, existem diversos intentos de ordem legislativa que visam inserir e regulamentar a Audiência de Custódia em nossa legislação (PEC n 112, de 04 de maio de 2011; Projeto de Lei $n^{0} 7.871$ de 08 de agosto de 2014; Projeto de Lei ${ }^{0} 470$ de 02 dezembro de 2014, PEC no 89, de 9 de julho de 2015).

Importante é sustentar que a referida Audiência não funciona apenas para a análise da legalidade acerca da prisão; sua principal finalidade é a de garantir direitos fundamentais ao imputado. Apresentar-se-á à autoridade judicial, o preso em flagrante delito no prazo de vinte e quatro horas depois de efetivada a prisão; dessa forma se possibilita o exercício do contraditório quanto aos fatos a este imputados, sua defesa pessoal e sua defesa técnica.

Nesse ponto, Lopes Jr e Rosa (2015) esclarecem que o diálogo ofertado ao imputado e ao juiz, possibilita a não antecipação de sentido, muitas vezes decorrente da simples leitura da peça acusatória ou do auto de prisão em flagrante. Sem dúvida, aqui "[...] reside o passo fundamental para o acolhimento da audiência de custódia." (SANTOS, 2015, p. 81). Concretiza-se o chamado contraditório prévio já introduzido no sistema jurídico penal brasileiro, por meio da Lei $n^{0}$ 12.403/2011 (SANTOS, 2015). 
Mais ainda, o respeito à medida possibilita uma harmonização do Processo Penal brasileiro aos Tratados Internacionais de Direitos Humanos, bem como a possível redução do encarceramento em massa enraizado no Brasil (LOPES JR.; PAIVA, 2015), visto que permite a análise de cada caso e observação da necessidade ou não de prisão cautelar ou demais medidas alternativas à prisão.

\section{AUDIÊNCIA DE CUSTÓDIA NO MARANHÃO: aplicação e efetividade}

No ano de 2014, a Corregedoria Geral da Justiça do Poder Judiciário do Estado do Maranhão publicou o Provimento CGJ no 14/2014, que alterava o teor do provimento no 12/2014, nas disposições que versavam acerca da verificação de regularidades das prisões ocorridas durante 0 plantão forense.

Chamou-se atenção para a situação atual do Sistema Carcerário do Maranhão, a superlotação dos estabelecimentos prisionais e a falta de locais suficientes para a custódia de presos provisórios no âmbito estadual. (MARANHÃO, 2014a). Destacou-se a excepcionalidade característica da prisão cautelar, bem como a fundamental necessidade de medidas emergenciais para evitar a superlotação nos estabelecimentos prisionais.

O Provimento $\mathrm{n}^{0} 14 / 2014$, em Artigo $1^{0}$, dispôs que ao Juiz criminal plantonista, quando receber o comunicado de prisão em flagrante, habeas corpus, pedido de arbitramento de fiança ou relaxamento de prisão, caberá decidir imediatamente sobre a soltura do autuado e/ou aplicação das medidas alternativas cabíveis, caso inexistam pressupostos para sua prisão temporária e/ou preventiva.

No entanto, em disposição feita por parágrafo único, situa o instituto da Audiência de Custódia como faculdade a ser realizada pelo critério de necessidade verificado à luz do entendimento do magistrado. Sendo somente possível, frisa, em se tratando de prisões em flagrante delito nas quais o Juiz plantonista vislumbrar a necessidade de conversão para prisão preventiva.

No mês de Dezembro do mesmo ano foi publicado o Provimento CGJ n 24/2014, também pela Corregedoria Geral da Justiça do Poder Judiciário Maranhense, no qual se regulamentava a Audiência de Custódia na comarca de São Luís. Há que se destacar o $§ 1^{\circ}$ do Artigo $1^{\circ}$ do referido ato, no qual dispõe que caso ocorra prisão em flagrante no plantão judicial criminal, "[...] e o juiz plantonista não se achar em condição de realizar a audiência de custódia, deverá consignar suas razões em despacho fundamentado." (MARANHÃO, 2014b), enviar cópia da sua decisão à Corregedoria-Geral de Justiça e remeter os autos ao juiz da Central de Inquéritos para que seja realizado 0 ato. Ou seja, carrega valor não obrigacional na realização da Audiência de Custódia em regime de plantão criminal, 


\section{AUDIÊNCIA DE CUSTÓDIA E SUA IMPLEMENTAÇÃO NA PRÁTICA PROCESSUAL PENAL DO ESTADO DO MARANHÃO}

na medida em que remete ao Juiz plantonista a faculdade da realização da Audiência de Custódia, ou não, em compatibilidade à sua possibilidade de presidir 0 ato.

Limita-se, também, a realização de Audiências no termo judiciário de São Luís, devendo o Juiz que a realizar, remeter os autos ao juízo competente após sua realização. 0 Artigo $2^{\circ}$ do referido provimento fixa o prazo de realização da Audiência de Custódia, pelos juízes da Central de Inquérito, em 48 horas contadas a partir do recebimento da comunicação da prisão.

Como justificativa para a publicação do Provimento n² 24/2014, a Des. Nelma Sarney Costa traz em suas considerações a) o caráter excepcional da restrição da liberdade individual, somente possível quando presentes os requisitos para adoção de medidas cautelares; b) a obrigação decorrente da disposição da Lei $n^{0}$ 12.403/2011 em ter o Juiz de converter a prisão em flagrante em prisão preventiva, quando não for o caso de seu relaxamento ou concessão de liberdade provisória, com ou sem medida cautelar alternativa; c) a necessidade de medidas permanentes que contribuam para melhorar o ambiente carcerário do Estado do Maranhão e a seletividade de presos provisórios, aplicando o monitoramento eletrônico e/ou outras medidas cautelares diversas da prisão, quando cabíveis; e d) a obediência aos dispositivos da CADH.

O que se depreende após a leitura das respectivas motivações do Prov. $n^{0} 24 / 2014$ é que existe uma falsa ideia sobre as funções da Audiência de Custódia. Insere-se nesta um viés reducionista de política para diminuição de índices de encarceramento estadual, mas se esquece de seu núcleo fundante, qual seja a função de medida de controle jurisdicional de atos da persecução criminal que, por vezes, estão associados a cometimento de ilegalidades, torturas e maus tratos, ou seja, agressões a direitos fundamentais e humanitários. (MARANHÃO, 2014b).

Há, portanto, uma confusão entre causa e consequência agregada ao Instituto da referida audiência. Sua Causa, ou seja, fator pelo qual se busca sua aplicação é a garantia de mais respeito a direitos fundamentais na ocorrência de prisões. Dessa forma, uma humanização maior ao processo penal brasileiro. Sua consequência ou efeito, de maneira imediata será o controle da legalidade prisional; e de maneira mediata será, sobremaneira, a redução do índice de prisões desnecessárias, e, consequentemente, redução de encarcerados.

Em 29 de Julho de 2015, o Tribunal de Justiça e Governo do Estado do Maranhão assinaram o termo de cooperação técnica n. 007/2015 (MARANHÃO, 2015), celebrando pacto com 0 Conselho Nacional de Justiça (CNJ) e o Instituto de Defesa do Direito de Defesa (IDDD), para a efetiva implantação do Projeto Audiência de Custódia. Esse termo de adesão trouxe como acordado entre os pactuantes que ambos estariam dispostos a fomentar e viabilizar a operacionalização da apresentação pessoal de autuados presos em flagrante delito à autoridade judiciária, no prazo máximo de 24 horas após sua prisão. 
Ou seja, aquele prazo para apresentação de pessoa presa em flagrante que, por meio do provimento $n^{0} 24 / 2014$, se daria em 48 horas, atualmente deverá acontecer em 24 horas após a efetiva prisão.

Em Dezembro do mesmo ano, por meio da Resolução $n^{0} 213$, de 15 de dezembro de 2015, o CNJ regulamenta a Audiência de Custódia bem como reitera o prazo de apresentação da pessoa presa em flagrante à Autoridade Judicial, antes já disposto no Termo de Cooperação Técnica nº 007/2015. (BRASIL, 2015). Porém, há que se falar da ausência de sanção quando do não cumprimento do referido prazo, sendo, portanto, evidente a permanência da cultura do não prazo no processo penal brasileiro. Logo, se persiste na crítica de que quando um ato processual possui um prazo para seu cumprimento, porém sem sanção aplicada em caso de descumprimento, resultará em ineficácia. (LOPES JR.; ROSA, 2015).

Em seu Artigo $10^{\circ}$, a Resolução $n^{0} 213$ do $\mathrm{CNJ}$ traz posicionamento interessante quanto à excepcionalidade da adoção de medidas cautelares diversas da prisão, bem como da prisão preventiva, quando cabível a concessão de liberdade provisória sem cautelares. Mais interessante é o posicionamento expresso do CNJ quanto à reavaliação periódica no que concerne à necessidade e adequação de sua manutenção.

Cabe ressaltar que, quando da aplicação de medidas cautelares, nestas se inclui a medida de prisão; deverá o Estado-Juiz, mesmo na ausência expressa das normas processuais, se manifestar acerca do prazo para tal reavaliação, dos motivos que fundamentam sua aplicação. Baseiase tal raciocínio em virtude do respeito obrigatório aos princípios que versam sobre o caráter provisional das medidas cautelares, ou seja, reavaliar se persistem os motivos que ensejaram a aplicação da referida medida.

Há também que se levar em consideração o princípio da provisoriedade das medidas cautelares, pois, a partir do referido princípio, caberia ao Estado-juiz o dever de manifestação expressa no decreto de prisão preventiva ou na aplicação das medidas alternativas ao cárcere. Tudo isso, também, pautado no princípio da dignidade da pessoa humana, uma vez que não se faz digno uma pessoa com liberdade restringida, sob qualquer natureza - prisional ou não -, em um processo criminal, sem conhecimento de prazo para reaver sua liberdade.

Porém, não havendo norma expressa nesse sentido, caberá à defesa requerer a expressa manifestação da Autoridade Judicial e o estabelecimento de prazos, tanto para a reavaliação dos motivos que ensejaram a aplicação de medidas cautelares, prisionais ou não, bem como seu prazo de duração.

Por exemplo, segundo relatório desenvolvido pela Unidade de Monitoramento Carcerário (MARANHÃO, 2016) acerca das audiências de custódia, desde o mês de outubro de 2014 até o mês 


\section{AUDIÊNCIA DE CUSTÓDIA E SUA IMPLEMENTAÇÃO NA PRÁTICA PROCESSUAL PENAL DO ESTADO DO MARANHÃO}

de setembro de 2015, foram realizadas 942 audiências. No primeiro ano, de todas as audiências realizadas (92), 53,27\% foram o percentual de prisões convertidas em medidas cautelares alternativas ao cárcere.

No segundo ano de monitoramento, 2015, até o dia 30 de setembro, foram realizadas 850 audiências de custódia, tendo como percentual de $46,35 \%$ as prisões convertidas em medidas cautelares alternativas, $0,35 \%$ de casos com o resultado de internações e tratamento CAPS, e $4 \%$ de relaxamento de prisão. Percebe-se que no ano de 2015, o resultado proporcionado pelas Audiências de Custódia realizadas foi de $50,7 \%$ de adoção da liberdade provisória (Tabela 1).

\section{Tabela 1 - Relatório Audiências de Custódia - Setembro 2015}

\section{Resumo das Audiências realizadas em 2014/2015.}

\begin{tabular}{|c|c|c|c|c|c|c|c|c|c|c|c|}
\hline \multirow{2}{*}{ Ano } & \multirow{2}{*}{ Mês } & \multirow{2}{*}{$\begin{array}{l}\text { Audiências } \\
\text { Realizadas }\end{array}$} & \multicolumn{6}{|c|}{ Liberdades Provisórias } & \multirow{2}{*}{$\begin{array}{c}\text { Relaxamento } \\
\text { de Prisão }\end{array}$} & \multirow{2}{*}{$\begin{array}{c}\text { Outros } \\
\text { Casos } \\
\text { *** }\end{array}$} & \multirow{2}{*}{$\begin{array}{c}\text { Decretação da } \\
\text { Prisão } \\
\text { Preventiva } \\
\end{array}$} \\
\hline & & & \multicolumn{2}{|c|}{$\begin{array}{l}\text { Cautelares } \\
\text { Comuns }\end{array}$} & \multicolumn{2}{|c|}{ Tornozeleiras } & \multicolumn{2}{|c|}{$\begin{array}{c}\text { Internaçōes e } \\
\text { Tratamento CAPS }\end{array}$} & & & \\
\hline \multirow{3}{*}{$2014 *$} & Outubro & 11 & 6 & $54,55 \%$ & & & & & & & 5 \\
\hline & Novembro & 41 & 20 & $48,78 \%$ & & & & & & & 21 \\
\hline & Dezembro & 40 & 15 & $37,50 \%$ & 8 & $20,00 \%$ & & & & & 17 \\
\hline TOTAL & & 92 & 41 & $44,57 \%$ & 8 & $8,70 \%$ & & & & & 43 \\
\hline \multirow{9}{*}{$2015 * *$} & Janeifo & 39 & II & $28,21 \%$ & 7 & $17,95 \%$ & & & I & & 20 \\
\hline & Fevereiro & 57 & 21 & $36,84 \%$ & 14 & $24,56 \%$ & & & 4 & & 18 \\
\hline & Março & 65 & 21 & $32,31 \%$ & 13 & $20,00 \%$ & 1 & $1,54 \%$ & 7 & & 23 \\
\hline & Abril & 53 & 11 & $20,75 \%$ & 20 & $37,74 \%$ & & & & & 22 \\
\hline & Maio & 61 & 5 & $8,20 \%$ & 22 & $36,07 \%$ & & & 1 & & 33 \\
\hline & Junho & 107 & 21 & $19,63 \%$ & 19 & $17,76 \%$ & 1 & $0,93 \%$ & & & 66 \\
\hline & Julho & 209 & 90 & $43,06 \%$ & 9 & $4,31 \%$ & & & l & & 109 \\
\hline & Agosto & 146 & 35 & $23,97 \%$ & 27 & $18,49 \%$ & I & $0,68 \%$ & 6 & & 77 \\
\hline & Setembro & 113 & 22 & $19,47 \%$ & 26 & $23,01 \%$ & & $0,00 \%$ & 14 & & 51 \\
\hline TOTAL & & 850 & 237 & $27,88 \%$ & 157 & $18,47 \%$ & 3 & $0,35 \%$ & 34 & & 419 \\
\hline
\end{tabular}

Estão incluidos os óbtos, que não contabilizam como sol to.

*Periodo de $17 / 10 / 2014$ à $05 / 12 / 2014$

** Periodo de 05/01/2015 à 30/09/2015.

Fonte: MARANHÃO. Tribunal de Justiça do Estado do Maranhão. Unidade de Monitoramento Carcerário. Relatório de Audiências de Custódia - Setembro 2015. São Luís - MA, 2015a. p, 3. Disponível em: http://www7.pcn.ma.gov.br/files/2015/11/Relat\%C3\%B3rio-Audi\%C3\%AAncia-Cust\%C3\%B3dia-Setembro2015.pdf?2f6c38. Acesso em: 6 nov 2015.

Em Março do ano de 2016, também por meio do Relatório de Audiências de Custódia (MARANHÃO, 2016), desenvolvido pelo Tribunal de Justiça, nota-se a permanência equilibrada da porcentagem referente à liberdade provisória e relaxamento de prisão com relação aos anos anteriores.

Somam 48,2\% o percentual das Audiências de Custódia cujo desfecho foi a adoção de Liberdade Provisória e Relaxamento de prisão. Cumpre informar que no referido ano, 417 foi o total de Audiências Realizadas; destas, apenas 211 foi o número de decretos de prisões provisórias (Tabela 2). 
Tabela 2 - Resumo das audiências realizadas em 2014/2016

\begin{tabular}{|c|c|c|c|c|c|c|c|c|c|c|c|}
\hline \multirow{2}{*}{ Ano } & \multirow{2}{*}{ Mês } & \multirow{2}{*}{$\begin{array}{l}\text { Audiências } \\
\text { Realizadas }\end{array}$} & \multicolumn{6}{|c|}{ Liberdades Provisórias } & \multirow[t]{2}{*}{$\begin{array}{l}\text { Relaxamento } \\
\text { de Prisão }\end{array}$} & \multirow[t]{2}{*}{$\begin{array}{c}\text { Outros } \\
\text { Casos } \\
* \neq * \\
\end{array}$} & \multirow[t]{2}{*}{$\begin{array}{c}\text { Decretação } \\
\text { da Prisão } \\
\text { Preventiva }\end{array}$} \\
\hline & & & \multicolumn{2}{|c|}{$\begin{array}{c}\text { Cautelares } \\
\text { Comuns }\end{array}$} & \multicolumn{2}{|c|}{ Tornozeleiras } & \multicolumn{2}{|c|}{$\begin{array}{c}\text { Internações e } \\
\text { Tratamento CAPS }\end{array}$} & & & \\
\hline \multirow{3}{*}{$2014^{*}$} & Outubro & 11 & 6 & $54,55 \%$ & & & & & & & 5 \\
\hline & Novembro & 41 & 20 & $48,78 \%$ & & & & & & & 21 \\
\hline & Dezembro & 40 & 15 & $37,50 \%$ & 8 & $20,00 \%$ & & & & & 17 \\
\hline TOTAL & & 92 & 41 & $44,57 \%$ & 8 & $8,70 \%$ & & & & & 43 \\
\hline \multirow{12}{*}{$2015^{* *}$} & Janeiro & 39 & 11 & $28,21 \%$ & 7 & $17,95 \%$ & & & 1 & & 20 \\
\hline & Fevereiro & 57 & 21 & $36,84 \%$ & 14 & $24,56 \%$ & & & 4 & & 18 \\
\hline & Março & 65 & 21 & $32,31 \%$ & 13 & $20,00 \%$ & 1 & $1,54 \%$ & 7 & & 23 \\
\hline & Abril & 53 & 11 & $20,75 \%$ & 20 & $37,74 \%$ & & & & & 22 \\
\hline & Maio & 61 & 5 & $8,20 \%$ & 22 & $36,07 \%$ & & & 1 & & 33 \\
\hline & Junho & 107 & 21 & $19,63 \%$ & 19 & $17,76 \%$ & 1 & $0,93 \%$ & & & 66 \\
\hline & Julho & 209 & 90 & $43,06 \%$ & 9 & $4,31 \%$ & & & 1 & & 109 \\
\hline & Agosto & 146 & 35 & $23,97 \%$ & 27 & $18,49 \%$ & 1 & $0,68 \%$ & 6 & & 77 \\
\hline & Setembro & 113 & 22 & $19,47 \%$ & 26 & $23,01 \%$ & & & 14 & & 51 \\
\hline & Outubro & 73 & 22 & $30,14 \%$ & 16 & $21,92 \%$ & & & 1 & & 34 \\
\hline & Novembro & 104 & 26 & $25,00 \%$ & 32 & $30,77 \%$ & & & 2 & 1 & 43 \\
\hline & Dezembro & 127 & 21 & $16,54 \%$ & 34 & $26,77 \%$ & & & 4 & 2 & 66 \\
\hline TOTAL & & 1154 & 306 & $26,52 \%$ & 239 & $20,71 \%$ & 3 & $0,26 \%$ & 41 & 3 & 562 \\
\hline \multirow{6}{*}{$2016^{* *}$} & Janeiro & 172 & 52 & $30,23 \%$ & 25 & $14,53 \%$ & & & 3 & 1 & 91 \\
\hline & Fevereiro & 147 & 46 & $31,29 \%$ & 25 & $17,01 \%$ & & & 13 & 2 & 61 \\
\hline & Março & 98 & 28 & $28,57 \%$ & 8 & $8,16 \%$ & & & 1 & 2 & 59 \\
\hline & Abril & & & & & & & & & & \\
\hline & Maio & & & & & & & & & & \\
\hline & Junho & & & & & & & & & & \\
\hline TOTAL & & 417 & 126 & $30,22 \%$ & 58 & $13,91 \%$ & & & 17 & 5 & 211 \\
\hline
\end{tabular}

Fonte: MARANHÃO, Tribunal de Justiça do Estado do Maranhão. Unidade de Monitoramento Carcerário. Relatório de Audiências de Custódia - Março 2016. São Luís - MA, 2016.

Nota-se, portanto, um verdadeiro avanço quanto à aplicação de medidas cautelares alternativas à prisão para adequar a máxima efetividade processual bem como restringir na menor medida a liberdade do imputado, principalmente quando se toma como parâmetro os registros de prisões cautelares após o advento da Lei 12.403 de 2011, onde a lógica judicial permaneceu vinculada ao protagonismo da prisão. (LOPES JR.; PAIVA, 2015).

Em quase um ano de Estudo desenvolvido pela Unidade de Monitoramento Carcerário do TJMA (de 17/10/2014 a 31/08/2015) (MARANHÃO, 2015), foi possível observar o índice de reincidência em infrações daqueles submetidos à audiência de custódia. Com o quantitativo de 813 acusados analisados, por meio dos sistemas, SIGO da Secretária de Segurança Pública do Estado, SIISP da Secretaria de Justiça e Administração Penitenciária, THEMIS e JURISCONSULT do Tribunal de Justiça do Maranhão, observou-se que 429 foi o número de audiências com resultado em liberdade (relaxamento de prisão e liberdade provisória com medidas cautelares). Desse total, apenas 25 foram as pessoas que voltaram a ter conflito com a Justiça, ou seja, somente $5,83 \%$ daqueles que saíram livres de prisão após a audiência de custódia é que voltaram a - supostamente - se envolver em infrações.

Pelo fato de se garantir, a partir de uma audiência, direitos fundamentais ao imputado, trabalha-se aqui a ideia de que em verdade se pauta em uma audiência de garantias, na qual o juiz garantidor exerce seu dever constitucional de zelar por direitos e regras primordiais ao devido processo legal, principalmente ao contraditório prévio. Nesse sentido, concorda-se com Santos (2015), pois o 


\section{AUDIÊNCIA DE CUSTÓDIA E SUA IMPLEMENTAÇÃO NA PRÁTICA PROCESSUAL PENAL DO ESTADO DO MARANHÃO}

autor expõe a incompatibilidade do termo audiência de custódia à sua verdadeira finalidade, sendo mais apropriado o termo audiência de garantia, por representar com maior fidelidade a natureza do instituto.

Tamanho é o grau de importância e necessidade de se garantir esse direito ao detido, que se assim não se proceder, toda e qualquer prisão será considerada ilegal. É o que se decidiu em sede de Habeas Corpus impetrado pela Defensoria Pública do Rio de Janeiro.

O Des. Luiz Noronha Dantas, ao analisar a decisão proferida em $1^{\text {a }}$ instância, reafirma tudo aquilo já dito, e destaca, principalmente, a força normativa que as disposições internacionais possuem no direito pátrio. No tocante à logística de custos para que se efetive a medida, quando da argumentação de que 0 ato não "[...] se coaduna com a realidade, eis que absolutamente inviável a realização da audiência imediatamente após a prisão de cada réu." (RIO DE JANEIRO, 2015), o Des. Luiz Noronha Dantas afirma ser o absurdo dos absurdos. Justificar a restrição de direitos fundamentais com base na falta ou na má gestão do Estado, é admitir que se vive em um Estado de desrespeito a Direitos.

\section{CONCLUSÃO}

A implementação do instituto da Audiência de Custódia, como medida processual de cumprimeto obrigatório, tem um atraso de mais de duas décadas desde a assinatura da CADH e 0 PIDCP pelo Brasil.

Não bastasse isso, ainda há diversas opiniões que propõem a não aplicação do referido instituto. Todavia, de acordo com os dados aqui trazidos, ressalta-se que o respeito à medida possibilita a harmonia entre o Processo Penal brasileiro e os Tratados Internacionais de Direitos Humanos.

Notável é a redução do encarceramento em massa, característico do sistema prisional brasileiro, pois possibita a análise de cada caso, pelo juiz competente, e a observação da necessidade ou não de prisão cautelar ou demais medidas alternativas à prisão.

No que tange às Audiências de Custódia e sua efetividade no Estado do Maranhão, já se nota a redução do índice de decretos de prisão preventiva, ou pelo menos um equilíbrio entre tais decretos e a adoção de medidas cautelares diversas.

\section{REFERENCIAS}

ANDRADE, M. F.; ALFLEN, P. R. Audiência de Custódia no processo penal brasileiro. Porto Alegre: Livraria do Advogado, 2016.

BRASIL, Senado Federal. Parecer $n^{0}$..., 2014. Relator Senador Humberto Costa. Projeto de Lei do Senado, $n^{0} 554$, de 2011, que estabelece prazo de 24 horas, contadas a partir da prisão em flagrante, 
para apresentação do preso à autoridade judicial. Brasília, DF, 2014. Disponível em: http://www.senado.leg.br/atividade/rotinas/materia/getTexto.asp?t=153845\&c=PDF\&tp=1. Acesso em 18 mai de 2016.

BRASIL. Conselho Nacional de Justiça. Resolução n 213 de 15 de Dezembro de 2015. Dispõe sobre a apresentação de toda pessoa presa à autoridade judicial no prazo de 24 horas. Brasília, DF, 2015. Disponível em: http://www.cnj.jus.br/busca-atos-adm?documento=3059. Acesso em 24 mai. 2016.

BRASIL. Presidência da República. Casa Civil. Lei n. 12.403, de 4 de maio 2011. Altera dispositivos do Decreto-Lei n 3.689 , de 3 de outubro de 1941 - Código de Processo Penal, relativos à prisão processual, fiança, liberdade provisória, demais medidas cautelares, e dá outras providências. Diário Oficial da União, Brasília, DF, 2011.

BRASIL. Senado Federal. Emendas apresentadas em turno suplementar; Substitutivo ao Projeto de Lei do Senado, $n^{0} 159$, de 2009, que dispõe sobre a reforma do código de processo penal. Brasília, DF, 2009a. Disponível em: http://www.senado.gov.br/atividade/materia/getPDF.asp?t=84807\&tp=1. Acesso em 18 mai de 2016.

BRASIL. Senado Federal. Parecer $\mathbf{n}^{0}$..., de 2010. Relator Senador Renato Casagrande. Projeto de Lei do Senado, $n^{0}$ 159, de 2009, que dispõe sobre a reforma do código de processo penal. Brasília, DF, 2010. Disponível em: http://www.senado.leg.br/atividade/rotinas/materia/getPDF.asp?t=84353\&tp=1. Acesso em: 18 maio 2016.

BRASIL. Supremo Tribunal Federal. RE 466343, Voto do Ministro Gilmar Mendes, Tribunal Pleno, julgamento em 3.12.2008. Dário da Justiça Eletrônico, Brasília, DF, 2009b.

GIACOMOLLI, N. 0 devido processo penal: abordagem conforme a Constituição Federal e o Pacto de São José da Costa Rica. 2. ed. São Paulo: Atlas, 2015.

LOPES JR, A.; PAIVA, C. Audiência de custódia e a imediata apresentação do preso ao juiz: rumo à evolução civilizatória do processo penal. Revista Liberdades, São Paulo, n. 17, p. 11-23, 2014.

LOPES JR., A.; ROSA, A. M. da. Processo penal no limite. 1. ed. Florianópolis: Empório do Direito, 2015.

MARANHÃO, Tribunal de Justiça do Estado do Maranhão. Provimento no 14, 24 de novembro de 2014. São Luís, 2014a. Des. Nelma Celeste Souza Silva Sarney Costa. Disponível em:

http://www.tjma.jus.br/cgj/visualiza/sessao/1581/publicacao/407410. Acesso em 19 mai. 2016.

MARANHÃO, Tribunal de Justiça do Estado do Maranhão. Provimento n² 24, 5 de dezembro, 2014. São Luís, 2014b. Des. Nelma Celeste Souza Silva Sarney Costa. Disponível em:

http://www.tjma.jus.br/cgj/visualiza/sessao/1559/publicacao/407902. Acesso em 24 mai. 2016.

MARANHÃO, Tribunal de Justiça do Estado do Maranhão. Unidade de Monitoramento Carcerário.

Relatório de Audiências de Custódia - Março 2016. São Luís - MA, 2016.

MARANHÃO. Tribunal de Justiça do Estado do Maranhão. Unidade de Monitoramento Carcerário. Relatório de Audiências de Custódia - Setembro 2015. São Luís - MA, 2015. Disponível em: http://www7.pcn.ma.gov.br/files/2015/11/Relat\%C3\%B3rio-Audi\%C3\%AAncia-Cust\%C3\%B3diaSetembro-2015.pdf?2f6c38. Acesso em 06 nov 2015. 
MENDES, G. F.; BRANCO, P. G. G. Curso de direito constitucional. 10 ed. rev. e atual. São Paulo: Saraiva, 2015.

RIO DE JANEIRO. Poder Judiciário. Gabinete da Presidência. Departamento de Processos da Presidência (DEPRE). Ofício PRES nº 275/2014. Rio de Janeiro, 2014. Disponível em: http://www.senado.leg.br/atividade/rotinas/materia/getPDF.asp?t=152687\&tp=1. Acesso em: 19 mai. 2016.

RIO DE JANEIRO. Tribunal de Justiça do Estado do Rio de Janeiro. Habeas Corpus $\mathrm{n}^{\circ} 0064910$ 46.2014.8.19.0000, $6^{\text {a }}$ Câmara Criminal, rel. Des. Luiz Noronha Dantas, decisão liminar de 25-012015. Rio de Janeiro, 2015.

ROSA, A. M. da. Guia compacto do processo penal conforme a teoria dos jogos. 3. ed. rev. atual. e ampl. Florianópolis: Empório do Direito, 2016.

SANTOS, C. I. Audiência de custódia ou sobre o óbvio ululante. Síntese de Direito Penal e

Processual Penal, Porto Alegre, n. 91, p. 77-120, 2015. Parte Geral - Doutrina.

SARLET, I.; MARINONI, L. G.; MITIDIERO, D. Curso de direito constitucional. São Paulo: Editora Revista dos Tribunais, 2012.

Notas

1 2. Há o caráter especial do Pacto Internacional dos Direitos Civis Políticos (art. 11) e da Convenção Americana sobre Direitos Humanos - Pacto de San José da Costa Rica (art. $7^{\circ}, 7$ ), ratificados, sem reserva, pelo Brasil, no ano de 1992. A esses diplomas internacionais sobre direitos humanos é reservado o lugar específico no ordenamento jurídico, estando abaixo da Constituição, porém acima da legislação interna. 0 status normativo supralegal dos tratados internacionais de direitos humanos subscritos pelo Brasil, torna inaplicável a legislação infraconstitucional com ele conflitante, seja ela anterior ou posterior ao ato de ratificação. Também é o entendimento expressado pelo Min. Gilmar Mendes em sede de Recurso Extraordinário (BRASIL, 2009b) - "[...] Portanto, diante do inequívoco caráter especial dos tratados internacionais que cuidam da proteção dos direitos humanos, não é difícil entender que a sua internalização no ordenamento jurídico, por meio do procedimento de ratificação previsto na Constituição, tem o condão de paralisar a eficácia jurídica de toda e qualquer disciplina normativa infraconstitucional com ela conflitante. [...] deixou de ter aplicabilidade diante do efeito paralisante desses tratados em relação à legislação infraconstitucional que disciplina a matéria [...]. Tendo em vista 0 caráter supralegal desses diplomas normativos internacionais, a legislação infraconstitucional posterior que com eles seja conflitante também tem sua eficácia paralisada".

2 Artigo $15^{\circ}$. O juiz das garantias é responsável pelo controle da legalidade da investigação criminal e pela salvaguarda dos direitos individuais cuja franquia tenha sido reservada à autorização prévia do Poder Judiciário, competindo-lhe especialmente: [...] III - zelar pela observância dos direitos do preso, podendo determinar que este seja conduzido a sua presença". (BRASIL, 2009a).

3 "Emenda no 170 - Plenário. [...] Dê-se a seguinte redação ao Art. 551: Art. 551 - Observado o disposto no art. 533, dentro em 24 (vinte e quatro) horas depois da prisão, será apresentado ao juiz competente o preso em flagrante, juntamente com 0 auto de prisão em flagrante acompanhado de todas as oitivas colhidas. Parágrafo Único: Nas comarcas em que a autoridade judiciária não estiver presente todos os dias, o preso será apresentado na primeira oportunidade em que 0 juiz comparecer à comarca". (BRASIL, 2009a).

4 "Emenda $n^{0} 171$ - Plenário. [...] Dê-se a seguinte redação ao art. 553, que passa a ter a seguinte redação: Art. 553 - Ao receber o auto de prisão em flagrante, o juiz, na presença do preso e após ouvi-lo, deverá:" (BRASIL, 2009a).

5 Os autores fazem menção ao Ofício-Circular n 033/03 da CGJ - Corregedoria Geral de Justiça do Tribunal de Justiça do Rio Grande do Sul, como importante iniciativa para a concretização e aplicação da Audiência de Custódia, mas que não obteve êxito significativo. 
6 Todas as manifestações das referidas instituições estão disponíveis no site do Senado (Disponível em: https://www25.senado.leg.br/web/atividade/materias/-/materia/102115?o=c. Acesso em 19 mai. 2016). 